\title{
Third Molar Removal and Orofacial Pain: a Population-Based Survey
}

\author{
Tatiana V. Macfarlane', Anthony S. Blinkhorn², Laura J. Stevenson³, Paul Coulthard ${ }^{4}$ \\ ${ }^{1}$ Aberdeen Pain Research Collaboration, Division of Applied Medicine, School of Medicine and Dentistry, University of \\ Aberdeen, Aberdeen, United Kingdom \\ ${ }^{2}$ Population Oral Health, Faculty of Dentistry, University of Sydney, Sydney, Australia \\ ${ }^{3}$ Dental Centre, H M S Heron, Royal Naval Air Station, Yeovilton, United Kingdom \\ ${ }^{4}$ Department of Oral and Maxillofacial Surgery, School of Dentistry, University of Manchester, United Kingdom
}

\author{
Corresponding Author: \\ Tatiana V. Macfarlane \\ Aberdeen Pain Research Collaboration, Division of Applied Medicine \\ School of Medicine and Dentistry, University of Aberdeen \\ Polwarth Building, Foresterhill, Aberdeen AB25 2ZD \\ United Kingdom \\ Phone: +441224551585 \\ Fax: +44 1224554761 \\ E-mail tatiana.macfarlane@abdn.ac.uk
}

\begin{abstract}
Objectives: The aim of the current study was to investigate whether there was a relationship between a history of third molar removal and the prevalence of orofacial pain in a sample of the general population.

Material and methods: A survey was conducted in South East Cheshire, United Kingdom (81\% participation rate). Information was collected using postal questionnaires $(\mathrm{n}=1510)$ and dental records $(\mathrm{n}=809)$.

Results: Participants who reported third molar extractions were more likely to report orofacial pain $(\mathrm{RR}=1.29 ; 95 \%$ confidence interval $[\mathrm{CI}] 1.01-1.65)$. Participants with a more recent history of extractions ( $<8$ years ago) as recorded in dental records were more likely to report orofacial pain compared to those who had all third molar present $(\mathrm{RR}=1.91 ; 95 \% \mathrm{CI} 1.10$ - 3.32). Conclusions: This research suggests that self-reported third molar removal is linked to self-reported orofacial pain, however evidence from one study is not sufficient to give an unequivocal answer.
\end{abstract}

Keywords: orofacial pain; molar, third; tooth, wisdom; tooth extraction; epidemiology.

Accepted for publication: 12 July 2010

To cite this article:

Macfarlane TV, Blinkhorn AS, Stevenson LJ, Coulthard P. Third Molar Removal and Orofacial Pain: a Population-Based Survey.

J Oral Maxillofac Res 2010 (Jul-Sep);1(3):e4

URL: http://www.ejomr.org/JOMR/archives/2010/3/e4/e4ht.pdf

doi: $10.5037 /$ jomr.2010.1304 


\section{INTRODUCTION}

Orofacial pain (OFP) includes pains whose origin is below the orbitomeatal line, above the neck and anterior to the ears and pain within the mouth [1]. It can be a symptom of various disorders, however the majority of OFP is due to dental causes (for example, toothache) and facial trauma, and in most cases it is acute. The remainder is considered chronic OFP, and temporomandibular disorders (TMD) represent one of the most common forms of chronic OFP. TMD is a collective term, for disorders characterized by joint pain, masticatory muscle tenderness, joint noises and restricted jaw movements. The percentage of the population presenting with TMD is estimated at $3-4 \%$, however up to a quarter of the population may report the symptoms during the past month $[2,3]$.

It has been suggested that there is a relationship between the removal of third molars and the postoperative onset of temporomandibular joint pain/dysfunction. As early as 1969 , Greene et al. [4] reported that $48 \%$ of patients with TMD attributed the onset of their symptoms to a specific event, including prolonged oral surgery procedures. However there is equivocal evidence on a relationship between TMD symptoms and third molars removal: while some studies supported this finding [5-8], others did not find any association [9-11]. These studies involved patient populations [4,9], university students $[\underline{5}, \underline{8}]$, health plan enrolees $[\underline{6}, 11]$ and dental service enrolees [7]. One study [10] involved cases diagnosed in clinic and controls from dental health survey. None of the above studies were conducted in general population, i.e. they were all prone to selection bias as not all people with OFP seek treatment and not everybody enrolled in health and dental plans. The general population will be different from patients attending clinics.

The aim of the current study was to investigate whether there was a relationship between a history of third molar removal and the prevalence of orofacial pain in a sample of the general population.

\section{MATERIAL AND METHODS}

The study was a four year follow-up of the population survey conducted by Macfarlane et al. [12]. The original survey included randomly selected participants aged 18 - 65 years registered with a general medical practice in South East Cheshire, North West England. Random selection ensured that the study population could represent equally all genders, ages, ethnicities and social class. As general practice registers cover more than $99 \%$ of the population in England (http://www.statistics.gov.uk) and access to most health service care is through the general medical practitioner, the practice age-sex resister is a convenient frame for a general population survey.

Ethical approval for the study was granted by South Cheshire Local Research Ethics Committee.

Sample size for the baseline survey was calculated using the results of a pilot study using OFP prevalence estimate of $25 \%$ [12]. Every participant in the main survey who gave permission to be contacted again was included in the follow-up survey (only 3 participants of the baseline survey did not wish to be contacted again). Each participant received a postal questionnaire, with follow-up of non-responders by a reminder postcard, questionnaire and, if necessary, a short questionnaire and a telephone call. The questionnaire consisted of demographic, psychological, body pain and OFP sections. OFP was defined as present if participants during the past month "had any pain in their face, mouth or jaws that has lasted for one day or longer". Body pain was defined as present if participants during the past month "had any ache or pain in the body which has lasted for one day or longer". Psychological distress was measured using the 12-item version of the General Health Questionnaire [13]. Deprivation was measured by the Townsend Index, an area-based score derived from postcode sectors or wards [14].

Participants were also asked if they had their wisdom teeth removed and permission to be contacted again. In addition, participants were asked permission for their dental records to be examined, and in case of positive reply, were asked to indicate the name and address of their dentist.

Information from dental records was extracted by one of two clinical examiners. Information regarding number, position and method of third molar removal was recorded. Data were extracted in duplicate (both clinical examiners) from 10 records to investigate reliability. One clinical examiner repeated data extraction from 10 dental records twice to investigate reproducibility.

The magnitude of association between third molar removal and OFP was described by the relative risk (RR). RR here is a measure of the risk of OFP in one group compared to the risk of OFP in another (reference) group. A relative risk of one means there is no difference between two groups in terms of their risk of OFP. A relative risk of greater than one or of less than one means that being exposed to a factor either increases (relative risk greater than one) or decreases (relative risk less than one) the risk of OFP. Cox regression [15] was used to estimate RR adjusted for potential confounders. The data were analysed using Stata 10 for Windows (StataCorp, LP, USA, 2008) and SPSS 16.0 for Windows (SPSS Inc., Chicago, 
IL, USA, 2008) statistical packages.

\section{RESULTS}

A total of 1680 persons $(81 \%$ adjusted participation rate after excluding those who were no longer registered with the practice, deceased or who were not able to complete the questionnaire due to illness or disability or expressed a wish at baseline not to be contacted again) participated in the follow-up survey, and the full study questionnaire was completed by 1510 participants. The remainder completed a short version of the questionnaire which did not include question on third molar removal. Adjusted participation rate was higher in women (83\%) compared to men $(77 \%)$ (Chi-square test $\mathrm{P}<0.001)$ and in affluent areas (83\%) compared to deprived areas (59\%) (Chi-square test $\mathrm{P}<0.001)$. Non-respondents were older (mean age 49 years $[\mathrm{SD}=12]$ ) then nonrespondents (mean age 44 years $[\mathrm{SD}=13])(\mathrm{t}$-test $\mathrm{P}<$ 0.001 ).

Of those who completed the full questionnaire, 295 (19\%) reported OFP, $1202(80 \%)$ did not report such pain and $13(1 \%)$ did not answer this question. Majority $(60 \%)$ of self-reported OFP was chronic, i.e. lasted for more than 3 months. The mean pain severity was 4.8 on 10 -point numerical analogues scale $(\mathrm{SD}=2.3)$ and $62 \%$ sought advice on OFP from a health professional.

Over half $(873,58 \%)$ of respondents did not report a history of perceived third molar extractions, 77 (5\%) did not answer this question, giving 560 (37\%) who reported third molar removal.

The majority of participants $(1060,70 \%)$ who completed the full questionnaire gave permission for their dental records to be examined, and indicated the name and address of their dentist. Eight hundred and sixty $(81 \%)$ participants were registered with four main dental practices in the study area; the remainder were registered with dentists in the surrounding areas. These distant practices were not visited, so only these four main practices were included, and 806 (94\%) patient records were found. In addition, one practice in the surrounding area with 3 patient records was used as a pilot site, giving total of 809 records. Median time of registration with a dentist was 14 years (range 1 day - 46 years) prior to completing the questionnaire.

There was an acceptable (Cohen's kappa $>0.6, \mathrm{P}<$ 0.05 ) agreement when reliability and reproducibility of information regarding third molars extracted from dental records. The minimum Cohen's kappa value was 0.61 , maximum 1.00 , median was 0.71 , indicating at least substantial agreement, according to classification by Landis and Koch [16].

To validate the answers in the questionnaire regarding perceived third molar removal, this question was cross tabulated against the extractions recorded by dentists (Table 1). Of those who reported at least one perceived extraction, 20 (37\%) had extractions recorded in dental records, while for those who did not report history of extractions in the questionnaire, this figure was 27 (6\%). All four third molars were present in $113(25 \%)$ of participants who did not report extractions. Only 9 (3\%) of participants who reported that they had third molars removed had all four third molars present.

Participants who reported third molar extractions in the questionnaire were more likely to report OFP (adjusted Relative Risk [RR] 1.29); (95\% confidence interval [CI] 1.01 - 1.65) (Table 2). When only information from the dental records was used and participants with all four molars present were compared to those with at least one extraction, the RR was 1.50 (95\% CI 0.90 - 2.49). However when time since last extraction was investigated, the increase was evident only in relatively recent extractions $(\mathrm{RR}=1.91,95 \%$ CI $1.10-3.32)$ for people with third molar extraction less than eight and a half years ago, whilst the number of third molars remaining did not show any particular pattern.

\section{DISCUSSION}

This population-based epidemiological study has provided evidence that individuals who report third molar extractions are more likely to report OFP. When extraction information was validated using dental records, this association was only found in relatively

Table 1. Validity of self-reported third molar extractions

\begin{tabular}{|c|c|c|c|c|}
\hline \multirow{2}{*}{$\begin{array}{l}\text { Information from the } \\
\text { Questionnaire }^{\mathrm{a}}\end{array}$} & \multicolumn{4}{|c|}{$\begin{array}{l}\text { Information from Dental Records } \\
\qquad \mathrm{N}(\%)\end{array}$} \\
\hline & $\begin{array}{l}\text { At least one third molar missing, no } \\
\text { information on removal }\end{array}$ & $\begin{array}{l}\text { At least one third molar } \\
\text { extraction }\end{array}$ & $\begin{array}{l}\text { All four third molars } \\
\text { present }\end{array}$ & Total \\
\hline Third molars not removed & $314(69.2)$ & $27(6.0)$ & $113(24.8)$ & $454(100)$ \\
\hline Third molars removed & $193(59.9)$ & $20(37.3)$ & $9(2.8)$ & $222(100)$ \\
\hline
\end{tabular}

anformation was missing for 33 participants. 
Table 2. Relationship between third molar extractions and orofacial pain (OFP)

\begin{tabular}{|c|c|c|c|c|}
\hline Factors & $\begin{array}{l}\mathrm{N} \text { in } \\
\text { group }\end{array}$ & $\begin{array}{l}\text { \% with } \\
\text { OFP }\end{array}$ & $\begin{array}{l}\text { RR }(95 \% \mathrm{CI}) \text { adjusted } \\
\text { for age and gender }\end{array}$ & $\begin{array}{l}\text { RR }(95 \% \text { CI }) \text { adjusted for } \\
\text { age, gender, deprivation, } \\
\text { pain in the body, } \\
\text { psychological distress }\end{array}$ \\
\hline \multicolumn{5}{|l|}{$\begin{array}{l}\text { Information from Questionnaire } \\
\text { Self-reported extractions }\end{array}$} \\
\hline Third molars not removed & 866 & 17.4 & 1.00 & 1.00 \\
\hline Third molars removed & 556 & 22.8 & $1.38(1.08-1.76)$ & $1.29(1.01-1.65)$ \\
\hline Missing data & 88 & & & \\
\hline \multicolumn{5}{|l|}{$\begin{array}{l}\text { Information from Dental records } \\
\text { Extractions }\end{array}$} \\
\hline All third molars present & 130 & 19.2 & 1.00 & 1.00 \\
\hline At least one third molar extracted & 151 & 27.8 & $1.50(0.91-2.48)$ & $1.50(0.90-2.49)$ \\
\hline $\begin{array}{l}\text { No information on extraction in record or missing } \\
\text { questionnaire data }\end{array}$ & 528 & & & \\
\hline \multicolumn{5}{|l|}{ Time since most recent extraction } \\
\hline All third molars present & 130 & 19.2 & 1.00 & 1.00 \\
\hline Extraction 2 - 99 months ago ${ }^{a}$ & 72 & 37.5 & $1.95(1.12-3.37)$ & $1.91(1.10-3.32)$ \\
\hline Extraction 100 - 558 months ago & 73 & 17.8 & $0.99(0.50-1.95)$ & $1.07(0.54-2.13)$ \\
\hline No information on date of extraction & 6 & & & \\
\hline \multicolumn{5}{|l|}{ Number of third molars present } \\
\hline All 4 present & 130 & 19.2 & 1.00 & 1.00 \\
\hline 3 & 112 & 22.3 & $1.27(0.73-2.21)$ & $1.24(0.71-2.16)$ \\
\hline 2 & 145 & 20.7 & $1.13(0.66-1.93)$ & $1.03(0.60-1.78)$ \\
\hline 1 & 139 & 23.0 & $1.32(0.83-2.11)$ & $1.29(0.76-2.20)$ \\
\hline All absent & 252 & 24.6 & $0.96(0.63-1.45)$ & $1.19(0.74-1.90)$ \\
\hline Information missing on at least one third molar & 28 & & & \\
\hline No information on OFP & 3 & & & \\
\hline
\end{tabular}

a 100 months was a median time since extraction and therefore was chosen as a cut-off point. No participants had extraction less than 2 month prior to questionnaire completion.

recent extractions.

Any dental intervention that alters the occlusion has the potential to alter the position of the mandibular condyle in the mandibular (glenoid) fossa and predispose to TMD symptoms [17]. The incidence of TMD has been shown to rise after 19 years of age. It has been suggested that this could be attributed to occlusal changes as a consequence of teeth exfoliation and eruption of permanent successors, or the eruption of third molars leading to overcrowded dental arches $[18,19]$. Third molar removal could lead to TMD development as a consequence of the required surgery, which may necessitate wide mouth opening and the application of relatively large forces to the posterior mandible. Traumatic arthritis has been reported after third molar removal although the occurrence is rare [20]. TMD patients with a history of trauma or nontemporomandibular joint-related operations have reported higher prevalence, severity and frequency of OFP than controls $[\underline{21}, \underline{22}]$. It has been postulated that nerve damage in hard and soft tissues can cause sensitisation of both peripheral and central neurons [9]. Hypothetically, the increased pain perception following surgical third molar removal could tip the threshold balance toward TMD.

There are methodological issues which need to be considered when examining the study results.

The study involves a sample of the population of one geographic area in the United Kingdom and therefore may not be representative. While the overall participation rate at follow-up was high, non-participants were more likely to be male, younger and from lower socioeconomic background.

Nevertheless, these differences would only affect the comparisons in the present study if the relationship between these factors and presence of OFP were different in those subjects who participated compared with those who did not. This seems unlikely.

All possible efforts were made to increase the participation. Questionnaires were posted together 
with a covering letter from the general medical practitioner informing practice members of the practice participation in the study. A reply paid envelope was enclosed. Posters about the study were placed in the medical practice. Non-respondents were followed up by a postcard reminder, a further questionnaire, and, if necessary, a short questionnaire and a telephone call.

Although there was a statistically significant increase in risk $(30 \%)$ of OFP associated with self-reported extractions, we did not find a statistically significant association between at least one third molar extraction determined from the dental records and OFP (50\% increased risk). Firstly, there was less statistical power when information from dental records was analysed, as not all participants who completed the questionnaire had information from dental records. Secondly, individual perception may play role in this discrepancy. However we have adjusted in the statistical analysis in both cases for other potential risk factors such as other body pain and psychological distress. Thirdly, it has been shown that that there was good correspondence between subjective self-reports of well-defined oral health conditions and clinical findings, for example the number of teeth and the presence of dentures [23]. Finally, there was a statistically significant increase in risk among participants with more recent extractions, which support the findings of Huang and Rue, who also found elevated risk in more recent extractions [7].

While the study has achieved high participation rate and acceptable reliability when extracting information from dental records, several problems were encountered. Although participants had reported third molar removal in the original questionnaire, it may not be entirely accurate. For approximately half of all cases, third molars were marked as absent in the records but with no record of extraction. It was impossible to determine from the notes whether third molars marked as absent in this way were: 1) congenitally absent; 2) unerupted; 3) had been extracted before the origin of the notes. This problem was accentuated in the older age groups, where early dental records were not available. Another issue was inconsistent charting of third molars. In rare cases it was obvious that after early extraction of first molars, third molars were being recorded. In some cases charting of the tooth could change several times throughout the notes. Better recording of dental notes would help resolve some of these problems in primary dental care research. In addition, this study is a crosssectional survey and therefore the associations we report are not necessarily causal.

\section{CONCLUSIONS}

This research has shown that there is a weak relationship between self-reported history of third molar removal and self-reported orofacial pain, and the depth and detail of evidence is still inconclusive.

\section{ACKNOWLEDGMENTS AND DISCLOSURE STATEMENTS}

The authors are grateful to staff and patients of Lawton House Surgery, dental practice of AR Mellor \& Associates, Canal Street Dental Practice, Moody Terrace Dental Practice and TDU Miller dental practice in Congleton, Cheshire, United Kingdom for their help with the study. We are also grateful to Dr. D. King, University of Manchester, Manchester, UK and Mrs. C. Mackie, Manchester Dental School, Manchester, UK, for help with access to dental records.

The authors report no conflicts of interest related to this study.

\section{REFERENCES}

1. Zakrzewska JM, Hamlyn PJ. Facial pain. In: Crombie IKCPR, Linton SJ, LeResche L, Von Korff M, editors. Epidemiology of Pain. Seattle: IASP; 1999. p. 171-202.

2. Greene CS, Marbach JJ. Epidemiologic studies of mandibular dysfunction: a critical review. J Prosthet Dent. 1982 Aug;48(2):184-90. Review. [Medline: 7050363] [doi: 10.1016/0022-3913(82)90110-X]

3. Macfarlane TV, Glenny AM, Worthington HV. Systematic review of population-based epidemiological studies of orofacial pain. J Dent. 2001 Sep;29(7):451-67. [Medline: 11809323] [doi: 10.1016/S0300-5712(01)00041-0]

4. Greene CS, Lerman MD, Sutcher HD, Laskin DM. The TMJ pain-dysfunction syndrome: heterogeneity of the patient population. J Am Dent Assoc. 1969 Nov;79(5):1168-72. [Medline: 5259143]

5. Raustia AM, Oikarinen KS. Effect of surgical removal of the mandibular third molars on signs and symptoms of temporomandibular dysfunction: a pilot study. Cranio. 1991 Oct;9(4):356-60. [Medline: 1820835]

6. Huang GJ, LeResche L, Critchlow CW, Martin MD, Drangsholt MT. Risk factors for diagnostic subgroups of painful temporomandibular disorders (TMD). J Dent Res. 2002 Apr;81(4):284-8. [Medline: 12097315] [doi: $\underline{10.1177 / 154405910208100412]}$ 
7. Huang GJ, Rue TC. Third-molar extraction as a risk factor for temporomandibular disorder. J Am Dent Assoc. 2006 Nov;137(11):1547-54. [Medline: 17082281] [FREE Full Text]

8. Akhter R, Hassan NM, Ohkubo R, Tsukazaki T, Aida J, Morita M. The relationship between jaw injury, third molar removal, and orthodontic treatment and TMD symptoms in university students in Japan. J Orofac Pain. 2008 Winter;22(1):50-6. [Medline: 18351034]

9. Berge TI. Incidence of chronic neuropathic pain subsequent to surgical removal of impacted third molars. Acta Odontol Scand. 2002 Mar;60(2):108-12. [Medline: 12020113] [doi: 10.1080/000163502753509518]

10. Threlfall AG, Kanaa MD, Davies SJ, Tickle M. Possible link between extraction of wisdom teeth and temporomandibular disc displacement with reduction: matched case control study. Br J Oral Maxillofac Surg. 2005 Feb;43(1):13-6. [Medline: 15620768 ] [doi: 10.1016/j.bjoms.2004.10.001]

11. Huang GJ, Drangsholt MT, Rue TC, Cruikshank DC, Hobson KA. Age and third molar extraction as risk factors for temporomandibulardisorder.JDentRes.2008Mar;87(3):283-7.[Medline:18296615][doi:10.1177/154405910808700313]

12. Macfarlane TV, Blinkhorn AS, Davies RM, Kincey J, Worthington HV. Oro-facial pain in the community: prevalence and associated impact. Community Dent Oral Epidemiol. 2002 Feb;30(1):52-60. [Medline: 11918576] [doi: $10.1034 / j .1600-0528.2002 .300108 . x$ ]

13. Goldberg DP, Williams P. A user's guide to the General Health Questionnaire. NFER-NELSON Publishers, Windsor. 1988.

14. Townsend P, Phillimore P, Beattie A. Health and Deprivation: inequality and the north. London: Croom Helm, 1988.

15. Cox DR. Regression models and life tables (with discussion). J. R. Statist. Soc. Series B 1972; 34:187-220.

16. Landis JR, Koch GG. The measurement of observer agreement for categorical data. Biometrics. 1977 Mar;33(1):159-74. [Medline: $\underline{843571]}$ [doi: 10.2307/2529310]

17. Lindquist JT. Extractions and TMJ. J Am Dent Assoc. 1988 Oct;117(5):556. [Medline: 3225371]

18. Fushima K, Akimoto S, Takamot K, Kamei T, Sato S, Suzuki Y. [Incidence of temporomandibular joint disorders in patients with malocclusion]. Nihon Ago Kansetsu Gakkai Zasshi. 1989;1(1):40-50. Japanese. [Medline: 2489192]

19. Winstanley RB. A retrospective analysis of the treatment of occlusal disharmony by selective grinding. J Oral Rehabil. 1986 Mar;13(2):169-81. [Medline: 3457134] [doi: 10.1111/j.1365-2842.1986.tb00649.x]

20. Moses JJ, Lange CR, Arredondo A. Septic arthritis of the temporomandibular joint after the removal of third molars. J Oral Maxillofac Surg. 1998 Apr;56(4):510-2. [Medline: 9541355]

21. Plesh O, Gansky SA, Curtis DA, Pogrel MA. The relationship between chronic facial pain and a history of trauma and surgery. Oral Surg Oral Med Oral Pathol Oral Radiol Endod. 1999 Jul;88(1):16-21. [Medline: 10442939] [doi: 10.1016/S1079-2104(99)70187-3]

22. Pullinger AG, Seligman DA. Trauma history in diagnostic groups of temporomandibular disorders. Oral Surg Oral Med Oral Pathol. 1991 May;71(5):529-34. [Medline: 2047090] [doi: 10.1016/0030-4220(91)90355-G]

23. Unell L, Söderfeldt B, Halling A, Paulander J, Birkhed D. Oral disease, impairment, and illness: congruence between clinical and questionnaire findings. Acta Odontol Scand. 1997 Apr;55(2):127-32. [Medline: 9176661] [doi: 10.3109/00016359709115404]

\section{To cite this article:}

Macfarlane TV, Blinkhorn AS, Stevenson LJ, Coulthard P. Third Molar Removal and Orofacial Pain: a Population-Based Survey.

J Oral Maxillofac Res 2010 (Jul-Sep);1(3):e4

URL: http://www.ejomr.org/JOMR/archives/2010/3/e4/e4ht.pdf

doi: $10.5037 /$ jomr.2010.1304

Copyright (C) Macfarlane TV, Blinkhorn AS, Stevenson LJ, Coulthard P. Accepted for publication in the JOURNAL OF ORAL \& MAXILLOFACIAL RESEARCH (http://www.ejomr.org), 12 July 2010.

This is an open-access article, first published in the JOURNAL OF ORAL \& MAXILLOFACIAL RESEARCH, distributed under the terms of the Creative Commons Attribution-Noncommercial-No Derivative Works 3.0 Unported License, which permits unrestricted non-commercial use, distribution, and reproduction in any medium, provided the original work and is properly cited. The copyright, license information and link to the original publication on (http://www.ejomr.org) must be included. 